\title{
The Study on Augmented Reality and Virtual Reality for Supporting Myanmar Tourists in Thailand
}

\author{
Waraporn Jirapanthong $^{1+}$, Parnu Boonyarattaphan ${ }^{2}$, Chaichana Jaruwannakorn ${ }^{3}$, Panomporn \\ Dokprakhon $^{4}$ \\ 1, 2, 3, 4 College of Creative Design and Entertainment Technology, Dhurakij Pundit University, Thailand
}

\begin{abstract}
Our research is contributed in two ways: firstly to study on the background and profile of tourists in Thailand, in particularly we focus on Myanmar tourists, and review the literature of applying AR/VR technologies recently. Secondly, we analyse the practical method and benefits towards applying of AR/VR technology to support the tourism in Thailand. This paper presents our study that we developed the survey on Myanmar tourists in Thailand. Additionally, the study aims to examine the main development of augmented reality (AR) and virtual reality (VR) research in tourism. It aims to pinpoint directions for tourism research on AR and VR applications. We then propose the approach to support the tourism business in Thailand focusing Myanmar tourists by applying the AR/VR technology.
\end{abstract}

Keywords: augmented reality (AR), virtual reality (VR), Myanmar tourists, Thailand tourism, Tourism business, AR/VR technology.

\section{Introduction}

Tourism becomes one of the most important sectors driving the Thai economy. It can continuously generate high income for Thailand. Whereas, the number of international tourist arrivals to Thailand in 2018 reached 38.12 million people, up 7.1 percent year on year. In particular, Myanmar tourists is one of the standout target group in travelling to Thailand over the past years. The number of Myanmar tourist arrivals to Thailand has been growing and it is expected to continue doing so in the coming decade.

Our research explores the opportunities and offers the support to increase the volume of Myanmar tourists in Thailand. By looking at the contexts in which Thailand tourism is regulated, directed and choreographed, we consider the constraints and opportunities which shape the ways in which the number of Myanmar tourists grows higher. International data sources are used to illustrate the way in which Myanmar tourists respond to Thailand tourism. We also studied the potential technologies and innovations in order to become new approach for supporting. Recently Augmented Reality (AR) and Virtual Reality technologies enable users to have interactive, reality-based experiences. The technologies provide the capabilities of computer generated display, sound, text and effects to enhance the user's real-world experience. The information can be virtual or real, e.g. seeing other real sensed or measured information such as electromagnetic radio waves overlaid in exact alignment with where they actually are in space.

In this paper, we present the study on the profile of Myanmar tourists in Thailand and the review of AR/VR research in tourism. The paper also presents the directions for applying AR/VR innovations for tourism. The direction of our approach to support the tourism business in Thailand focusing Myanmar tourists by applying the AR/VR technology is presented. The methodology of our work is presented in Section 2, the findings is then presented in Section 3, and the proposed approach is presented in Section 4.

\footnotetext{
+ Corresponding author. Tel.: +66(0)9547300

E-mail address: waraporn.jir@dpu.ac.th
} 


\section{Methodology}

The literature review was conducted between January and April 2019. The review consists of two parts: Myanmar tourism and AR/VR background.

For the background and survey on Myanmar tourists in Thailand, we have performed the research survey and analysed based on the sources, for example:

- Euromonitor International. (2018). Passport: Travel in Thailand.

- Euromonitor International. (2018). Passport: Tourism Flows in Thailand

- CAPA Airport Traffic Database. (2017). Centre for Aviation and Thailand's Ministry of Tourism and Sports. Retrieved from https://centreforaviation.com/data/profiles/investor/airports-of-thailand-aot

Additionally, AR/VR-related refereed journal publications were searched from four major online databases (as suggested by Law et al., 2014), namely, the following:

- EBSCOhost’s Hospitality and Tourism Complete (http://search.ebscohost.com).

- Emerald Management e-Journals (www.emeraldinsight.com); and

- Sage (http://online.sagepub.com);

- Science Direct (www.sciencedirect.com);

\section{Findings}

\subsection{Marketing Segmentation of Myanmar Tourism in Thailand}

According to the literature review, we have narrowed down the market segmentation of Myanmar tourists in Thailand. The number of trips between 2013-2018 from Myanmar to Thailand have been grown: 173300, 207700, 262800, 363900, 398400, 428200 trips [1]. The trips from Myanmar was 19th out of all arrivals. The forecast number of trips between 2018-2023 from Myanmar to Thailand are: 428200, $467400,519800,574800,634900,702300$ trips [1]. It is forecasted as the 18th out of all arrivals.

Considering the minimum wage [2], the average annual income [3], the proportion of people under working life stage of $42.36 \%$ [4], and taken the estimated poverty rate of $37 \%$ [5] [6] in to consideration, the estimated market size is around 8.62 million people.

Additionally, it is found that Myanmar's middle class continues to grow, driving up spending [7]. The majority of Myanmar tourists are aged between 35-44 and 45-54 years old [8]. Myanmar tourists prefer natural and cultural tourism. To Thailand, they are also interested in many historical sites (Ayutthaya, Bangkok), Thai foods, Thai massage, night life (Bangkok, Pattaya), shows (Phuket, Pattaya, Bangkok) [9]. Myanmar's middle class working in major cities such as Yangon have an average earning of \$300-\$350 a month [2] [10].

\subsection{Gains and Pain Points of Myanmar Tourism in Thailand}

Regarding the study, we also analysed the gains and pain points of Myanmar tourists outbound towards Thailand. Firstly, as smartphone penetration continues to accelerate in Myanmar, the next phase of digital adoption will be e-commerce and mobile banking. While the e-commerce industry is still in the infant stage, majority of visitor traffic comes from smart phones, with consumers showing appreciation of the convenience of shopping on the go [11].

Secondly, with the country gravitating towards integrating smartphones actively in their daily lives, this is where tech start-ups can come in to cater to the basic needs of consumers especially in the financial, healthcare and educational sectors, thus boosting Small and Medium-sized Enterprises (SME) innovation [11].

Thirdly, while social media continues to be the predominant mode of engagement, businesses should effectively integrate online and offline marketing through a 'customer oriented' approach [11]. Although, the use of social media is rapidly growing for younger generation but the percentage is still not high especially, in the age of 35-44 and 45-54 years old, those are found being social media audience only 7.8\% and $3.3 \%[8]$. 
Fourthly, the proportion of Thai people speaking English is still low [9]. Next, the traffic condition in major cities of Thailand are very poor. Driving behaviour are also considered not so safe and many tourists have experienced bad taxi in Thailand [11] [9].

In addition to, the number of trips during 2013 - 2018 from Myanmar to Thailand has been growing. As shown in Figure 8, the green line graph presents the number of trips were 207700, 262800, 363900, 398400, and 428200, respectively. Whereas the blue line graph presents the forecast number of trips during 2019 2023. It is expected to reach the higher numbers of trips from Myanmar to Thailand as 467400, 519800, 574800, 634900, and 702300, respectively.

\subsection{Experience on Virtual Reality and Augmented Reality Technologies}

According to the researches, the use of AR/VR applications leads user-centered outcomes and drives consumer perspectives. Some research studied the consequences of AR/VR experience. It is pointed out that behavioural intentions are positively influenced. The studied behavioral intentions include intention to use/reuse AR/VR technologies [12][13][14], to visit the real destination [15][16], to revisit a destination [17] or an attraction [18], to purchase [19][20], to recommend [21][22], to share information with others within the application or beyond over a much larger social network [23] and to pay more [24].

Moreover, the unifying framework is proposed to present the users' perspectives. The framework provides both academics and practitioners with a synthesis of the key constructs and research findings associated with the application of VR/AR technologies in tourism and hospitality. The framework locates the stimuli, dimensions and consequences of AR/VR-related user behaviour and experience [25]. The stimuli i.e. service environment, individual differences, interpersonal factors, and feeling of presence drive the components of instrumental, experimental, psychological, and social dimensions. And the dimensions lead the consequences i.e. learning outcomes, emotional response, satisfaction, service experience, attitude, values, marketing effectiveness, destination image, awareness, and behavioural intentions.

\subsection{Theoretical Development in Virtual Reality and Augmented Reality}

The main development of AR/VR research in hospitality and tourism in the period from 2000 to March 2018. Using the existing VR/AR technological applications is the most commonly adopted method. These applications include mobile phone apps [18] [19] [14], augmented smart glasses [26] [27], wearable Google Glass/cardboard VR viewer [28] [29], wearable VR head-mounted displays [22], onsite GPS-based AR application [30], online 3D virtual tour provided by tourism websites [31], computer graphical reconstruction of historical towns [32], AR printed [33] and Second Life programs for tourism destinations [34] and for hospitality and tourism education (Deale,2013;Hsu,2012;Penfold,2009). [35] used a Museum Zoom Google Glass application (i.e. Glassware), which was designed to improve the visitor experience in an art gallery in the UK. And other AR/VR applications supported for tourism business [36] [24].

\section{Our Approach}

Regarding our study, we analysed and designed the framework for adopting AR technology to support tourism business, particularly for Myanmar tourists in Thailand. The prototype tool is designed to be available on mobile phone platforms. The application also includes a program for tourism destinations and for hospitality and tourism education in Thailand. The main feature is to display the virtual tour that provides hidden information in a real environment. This feature offers, for instance, the virtual presence of an AR display of a painting in a video scenario describing a museum experience. All information regarding objects in museum are prepared in term of an explanation along with a short video demonstrating AR in a museum context.

\section{Discussion and Future work}

Our research focuses on how to support the tourism business, particularly Myanmar tourists in Thailand. We studied the background of Myanmar tourists in Thailand for last years and the literature review of AR/VR technology. We then proposed the approach of developing an AR-based tool to support Myanmar tourists. Particularly, we studied the places and activities of Myanmar tourists in Thailand. The prototype 
tool of AR-based application was developed and allowed the stakeholders to experience the scenarios. This assists the stakeholders have virtual experience regarding the attractive places and more easily make a decision for traveling to Thailand. The stakeholders have positive attitudes towards the use of the prototype.

We plan to create a larger number of scenarios which include more attractive places and points in Thailand. It is therefore believed that the approach could be extended and enhanced to support a better way. In addition, sophisticated techniques for visualization could support the use of the prototype tool more efficiently. However, the prototype tool takes a long time to be processed depending on the size and number of scenarios. More work needs to be done to optimize the processing time.

\section{Acknowledgements}

This research is partly funded by TTT.

\section{References}

[1] Euromonitor International. (2018). Passport: Tourism Flows in Thailand

[2] Inter Global Reach, Local Expertise. (2018). The Rising Middle Class in Myanmar. Retrieved from https://www.intergroup.asia/blog/the-rising-middle-class-in-myanmar, October 10th, 2018.

[3] Myanmar's middle class continues to grow, driving up spending, https://kasikornbank.com/internationalbusiness/en/AEC/Intelligence/Pages/201901_WTW_Myanmar.aspx

[4] Index Mundi. Myanmar’s demographics profile 2018 Retrieved from https://www.indexmundi.com/burma/demographics_profile.html, January 20th, 2018

[5] Check in Price. (2019). Average and Minimum Salary in Yangon, Myanmar Retrieved from https://checkinprice.com/average-and-minimum-salary-in-yangon-myanmar/, March 7th, 2019

[6] Trading Economics. (2019). Myanmar Minimum Wage.

Retrieved from https://tradingeconomics.com/myanmar/minimum-wages

[7] The Straits Times Asia. (2018). Myanmar raises minimum wage as economy staggers.

Retrieved from https://www.straitstimes.com/asia/se-asia/myanmar-raises-minimum-wage-to-s480-a-day-aseconomy-staggers, Jan 3rd, 2018

[8] CEIC. (2018). Thailand Household Income per Capita.

Retrieved from https://www.ceicdata.com/en/indicator/thailand/annual-household-income-per-capita

[9] Aung Phyo. (2015). Myanmar Moves Up in Income Bracket. Myanmar Business Today. Retrieved from https://www.mmbiztoday.com/articles/myanmar-moves-income-bracket

[10] Digital 2019 Myanmar (January 2019) v01. (2019). Retrieved from https://www.slideshare.net/DataReportal/digital-2019-myanmar-january-2019-v01

[11] University of Thai Chamber of Commerce Journal. (2015). Myanmar’s Travel Behaviour, Media Exposure and Perception on Thai Cultural Universals. Associate Professor Dr. Kanchana Chokriensukchai.

[12] Kim, H.C. and Hyun, M.Y. (2016), "Predicting the use of smartphone-based augmented reality (AR): does telepresence really help?”, Computers in Human Behavior, Vol. 59, pp. 28-38.

[13] Kourouthanassis, P., Boletsis, C., Bardaki, C. and Chasanidou, D. (2015), "Tourists responses to mobile augmented reality travel guides: the role of emotions on adoption behavior”, Pervasive and Mobile Computing, Vol. 18, pp. 71-87.

[14] Rauschnabel, P.A., Rossmann, A. and tom Dieck, M.C. (2017), “An adoption framework for mobile augmented reality games: the case of pokémon go”, Computers in Human Behavior, Vol. 76, pp. 176-186.

[15] Pantano, E. and Servidio, R. (2011), “An exploratory study of the role of pervasive environments for promotion of tourism destinations”, Journal of Hospitality and Tourism Technology, Vol. 2 No. 1, pp. 50-65.

[16] Tussyadiah, I.P., Wang, D., Jung, T.H. and tom Dieck, M.C. (2018b), "Virtual reality, presence, and attitude change: empirical evidence from tourism”, Tourism Management, Vol. 66, pp. 140-154.

[17] Chung, N., Lee, H., Kim, J.Y. and Koo, C. (2018), “The role of augmented reality for experience-influenced 
environments: the case of cultural heritage tourism in Korea”, Journal of Travel Research, Vol. 57 No. 5, pp. 627643.

[18] Chung, N., Han, H. and Joun, Y. (2015), “Tourists' intention to visit a destination: the role of augmented reality (AR) application for a heritage site”, Computers in Human Behavior, Vol. 50, pp. 588-599.

[19] Javornik, A. (2016), “It’s an illusion, but it looks real!' consumer affective, cognitive and behavioral responses to augmented reality applications”, Journal of Marketing Management, Vol. 32 Nos 9/10, pp. 987-1011.

[20] Papagiannidis, S., Pantano, E., See-To, E.W. and Bourlakis, M. (2013), "Modelling the determinants of a simulated experience in a virtual retail store and users’ product purchasing intentions”, Journal of Marketing Management, Vol. 29 Nos 13/14, pp. 1462-1492.

[21] Kim, J. and Hardin, A. (2010), “The impact of virtual worlds on word-of-mouth: improving social networking and servicescape in the hospitality industry”, Journal of Hospitality Marketing and Management, Vol. 19 No. 7, pp. 735-753.

[22] Marasco, A., Buonincontri, P., van Niekerk, M., Orlowski, M. and Okumus, F. (2018), "Exploring the role of next-generation virtual technologies in destination marketing”, Journal of Destination Marketing and Management, Vol. 9, pp. 138-148, available at: https://doi.org/10.1016/j.jdmm.2017.12.002

[23] Kounavis, C.D., Kasimati, A.E. and Zamani, E.D. (2012), "Enhancing the tourism experience through mobile augmented reality: challenges and prospects”, International Journal of Engineering Business Management, Vol. 4, pp. 1-6.

[24] He, Z., Wu, L. and Li, X.R. (2018), "When art meets tech: the role of augmented reality in enhancing museum experiences and purchase intentions”, Tourism Management, Vol. 68, pp. 127-139.

[25] Harris, K. and Baron, S. (2004), “Consumer-to-consumer conversations in service settings”, Journal of ServiceResearch,Vol.6No.3,pp.287-303.

[26] Rauschnabel, P.A. and Ro, Y.K. (2016), “Augmented reality smart glasses: an investigation of technology acceptance drivers”, International Journal of Technology Marketing, Vol. 11 No. 2, pp.123-148.

[27] tomDieck,M.C.,Jung,T.and Han,D.I.(2016a), “Mapping requirements for the wearable smart glasses augmented reality museum application”, Journal of Hospitality and Tourism Technology, Vol. 7 No.3,pp.230-253.

[28] Rauschnabel, P.A., Brem, A. and Ivens, B.S. (2015), "Who will buy smart glasses? Empirical results of two premarket-entry studies on the role of personality in individual awareness and intended adoption of google glass wearables”, Computers in Human Behavior, Vol. 49, pp.635-647.

[29] tom Dieck, M.C., Jung, T.H. and tom Dieck, D. (2016b), “Enhancing art gallery visitors’ learning experience using wearable augmented reality: generic learning outcomes perspective”, Current Issues in Tourism, Vol. 21 No. 17, pp. 1-21, available at: https://doi.org/10.1080/ 13683500.2016.1224818

[30] Han, D.I., tom Dieck, M.C. and Jung, T. (2018), “User experience model for augmented reality applicationsinurbanheritagetourism”,JournalofHeritageTourism,Vol.13No.1,pp.46-61.

[31] Hyun, M.Y .and O’Keefe, R.M.(2012), “Virtual destination image :testing at elepresence model”, Journal ofBusinessResearch,Vol.65No.1,pp.29-35.

[32] Mosaker, L. (2001), “Visualising historical knowledge using virtual reality technology”, Digital Creativity,Vol.12No.1,pp.15-25.

[33] Yao yune yong, G., Foster, J., Johnson, E. and Johnson, D. (2016), “Augmented reality marketing: consumer preferences and attitudes toward hypermedia print ads”, Journal of Interactive Advertising,Vol.16No.1,pp.16-30.

[34] Mascho, E. and Singh, N. (2014), “Virtual tourism: use of 'second life’ for destination marketing”, Anatolia,Vol.25No.1,pp.140-143.

[35] Tussyadiah, I.P., Jung, T.H. and tom Dieck, M.C. (2018a), “Embodiment of wearable augmented reality technology in tourism experiences”, Journal of Travel Research, Vol. 57 No. 5, pp.597-611.

[36] tom Dieck, M.C. and Jung, T. (2018), “A theoretical model of mobile augmented reality acceptance in urbanheritagetourism”,CurrentIssuesinTourism,Vol.21No.2,pp.154-174. 